\title{
Fission thrust sail as booster for high $\Delta v$ fusion based propulsion
}

\author{
Frederik Ceyssens $^{\mathrm{a}}$ - Kristof Wouters ${ }^{\mathrm{b}}$ - Maarten Driesen ${ }^{\mathrm{c}}$ \\ ${ }^{a}$ KULeuven, dept. ESAT. Kasteelpark Arenberg 10, 3001 Leuven,Belgium. \\ Corresponding author. E-mail: fceyssen@esat.kuleuven.be. Tel.: 003216321093 \\ Other affiliations: Icarus Interstellar, USA \\ ${ }^{b}$ Xenics corporation, Belgium. \\ ${ }^{c}$ Peira corporation, Belgium.
}

\begin{abstract}
The fission thrust sail as booster for nuclear fusion-based rocket propulsion for future starships is introduced and studied. First order calculations are used together with Monte Carlo simulations to assess system performance. If a D-D fusion rocket such as e.g. considered in Project Icarus has relatively low efficiency $(\sim 30 \%)$ in converting fusion fuel to a directed exhaust, adding a fission sail is shown to be beneficial for the obtainable delta-v. Additionally, this type of fission-fusion hybrid propulsion has the potential to improve acceleration and act as a micrometeorite shield.
\end{abstract}

KEYWORDS: Fission-fusion hybrid; Fusion propulsion; Fission propulsion; Project Icarus; Thrust sail;

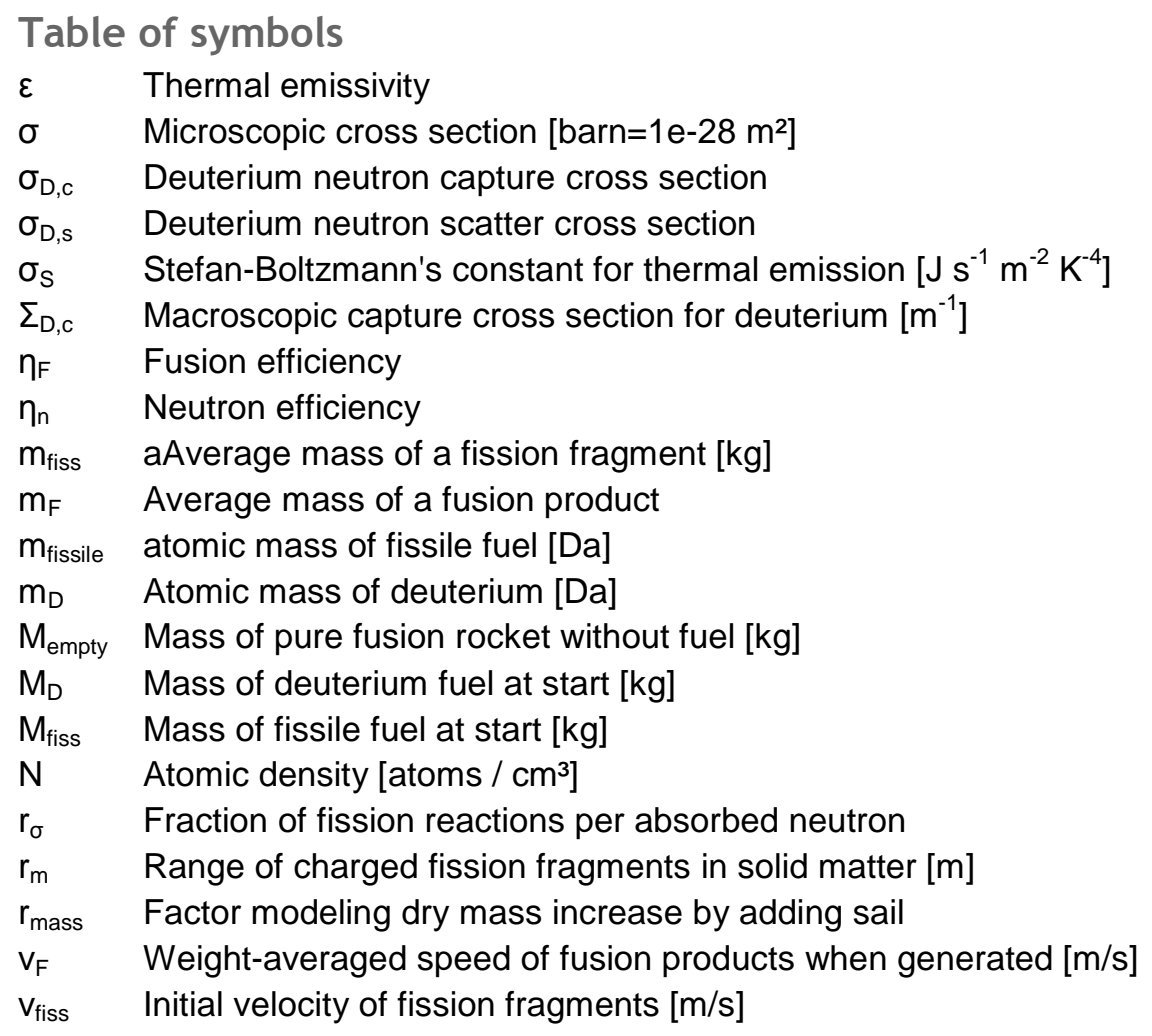


$<v_{\text {surf }}>$ Average $x$ speed of fission particles at sail surface

\section{Introduction}

The main lesson the rocket equation teaches is the need for high exhaust speed in order to enable the rocket to reach high velocity [1] [2]. Many advanced nuclear propulsion concepts are based on the high speed of the reaction products of nuclear fission and fusion reactions, which are in the order of $10^{7} \mathrm{~m} / \mathrm{s}$ $(3.5 \% \mathrm{c})$. These reaction products are then in some way directed out of the rocket before they lose most of their energy by thermalizing collisions with lower energy particles from the reaction mass or with structural parts of the rocket. If this can be achieved, according to the rocket equation a speed $\Delta v$ of about $10 \% \mathrm{c}$ is reachable with a single stage rocket with a mass ratio of 20 . Examples of such propulsion concepts include the fission fragment rocket [3] and pulsed fusion based rockets [4]-[8].

Especially for interstellar missions, which are now only being conceptualized, a high $\Delta v$ will be of paramount importance. In the Icarus concept [6]-[8] the use of fusion rockets is targeted, of which the charged reaction products are deflected by a magnetic nozzle and directed backwards into space. Of course, the resulting uncharged neutrons cannot be deflected magnetically. The purpose of this paper is to assess if it would make sense to use these neutrons to incite nuclear fission reactions to generate additional propulsion force.

More specifically, the examined case is that of a so-called fission sail or thrust sheet, attached to the spaceship. The fission sail would be made out of an inert material, covered on the inner side with a thin film of fissionable material exposed to the neutron flux generated by the fusion reaction in the main engine. The low thickness of the fissionable material film would allow a significant fraction of the fission reaction products to escape at high speed, causing additional propulsive force. The radioisotope or fissile element-covered sail concept was originally proposed by Mockel [9], but not explored in combination with neutrons from a nuclear fusion engine as done in this work. The concept is shown in figure 1, with some additional features such as neutron moderation introduced later in this paper. The driving fusion reacting considered here is D-D fusion, which is a reasonable compromise between feasibility and charged particle production. Other non-sail types of fission-fusion hybrids can be found in literature [10][11]. 


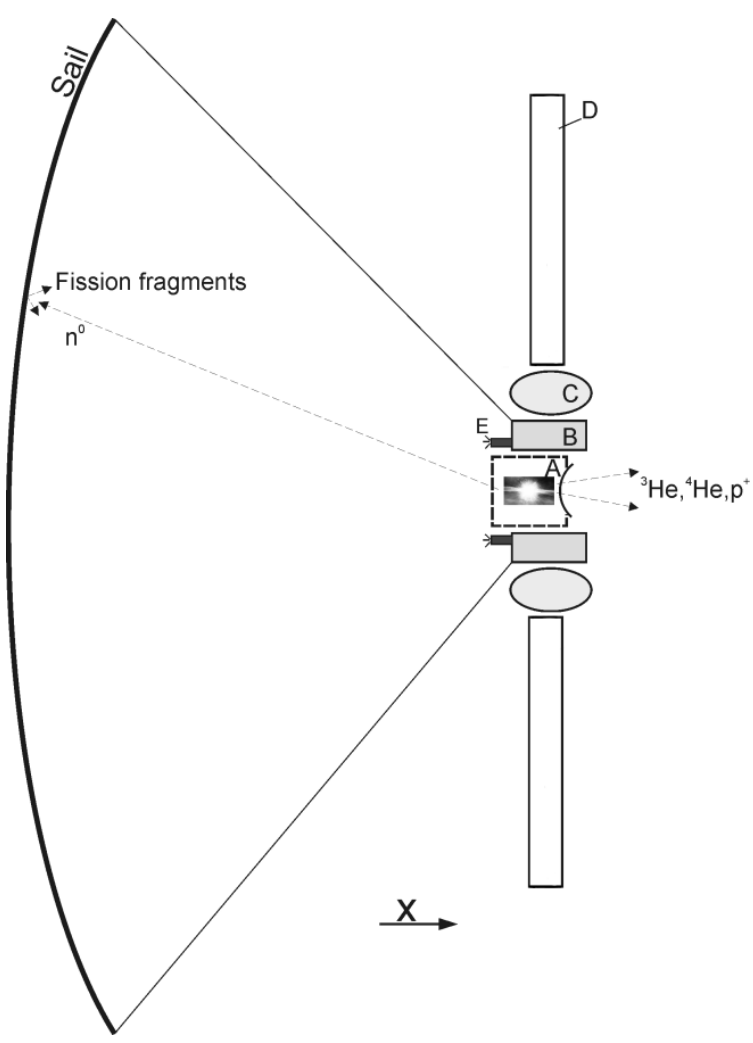

Figure 1: Fission Thrust Sail concept. A: fusion reactor with magnetic nozzle, partially surrounded by a moderator (dashed line in front of reactor) to slow down the produced neutrons heading for the sail. B: main ship structure including payload. C: deuterium fuel tank. D: Heat radiator. E: Fission fuel store and evaporation source for sail regeneration. The sail consists of a backplane with a fissile material coating on its inner side. Not shown: insulation to protect ship from thermal radiation from the sail. Drawing is conceptual and not to scale.

\section{Basic nuclear reactions}

The $D-D$ reaction is as follows:

$(50 \%) \mathrm{D}+\mathrm{D} \rightarrow \mathrm{T}(1.01 \mathrm{MeV})+\mathrm{p}^{+}(3.02 \mathrm{MeV})$

$(50 \%) \mathrm{D}+\mathrm{D} \rightarrow{ }^{3} \mathrm{He}(0.82 \mathrm{MeV})+\mathrm{n}^{0}(2.45 \mathrm{MeV})$

The produced $T$ reacts further:

$\mathrm{D}+\mathrm{T} \rightarrow{ }^{4} \mathrm{He}(3.5 \mathrm{MeV})+\mathrm{n}^{0}(14.1 \mathrm{MeV})$

The total reaction being:

$5 \mathrm{D} \rightarrow{ }^{3} \mathrm{He}+{ }^{4} \mathrm{He}+2 \mathrm{n}^{0}+\mathrm{p}^{+}$

The properties of the reaction products are displayed in more detail in table 1 . In that table, it can also be seen that the fusion products from the D-D reaction have a speed similar to that of the average fission fragments. The rest mass and momentum of the latter are much higher, though. 


\begin{tabular}{|l|l|l|l|l|}
\hline & Ek [MeV] & speed [\%c] & rest mass $[\mathrm{kg}]$ & momentum $[\mathrm{kg} \mathrm{m} / \mathrm{s}]$ \\
\hline $\mathrm{p}^{+}$ & 3.02 & 5.7 & $1.67 \mathrm{E}-27$ & $2.85 \mathrm{E}-20$ \\
\hline${ }^{4} \mathrm{He}$ & 3.5 & 3.1 & $6.68 \mathrm{E}-27$ & $6.12 \mathrm{E}-20$ \\
\hline${ }^{3} \mathrm{He}$ & 0.82 & 1.7 & $5.01 \mathrm{E}-27$ & $2.56 \mathrm{E}-20$ \\
\hline $\mathrm{n}^{0}$ & 2.45 & 5.1 & $1.67 \mathrm{E}-27$ & $2.56 \mathrm{E}-20$ \\
\hline $\mathrm{n}^{0}$ & 14.1 & 12.2 & $1.67 \mathrm{E}-27$ & $6.18 \mathrm{E}-20$ \\
\hline $\begin{array}{l}\text { aver. } \\
\text { product (excluding } \\
\text { neutrons) [12] }\end{array}$ & 175.8 & 4.0 & $1.97 \mathrm{E}-25$ & $2.36 \mathrm{E}-18$ \\
\hline
\end{tabular}

Table 1: reaction products of $D-D$ fusion reaction. Relativistic formulas are used to calculate speed and momentum out of kinetic energy Ek and rest mass. The weight-averaged speed of charged fusion products at the time of generation is $2.9 \%$ c. The weight-averaged speed of all fusion product particles is $v_{F}=2.65 \% c$. In this calculation, the neutron speeds are multiplied by $2 / \pi^{2}$ to account for their uniform distribution over all angles as they cannot be deflected by a magnetic nozzle and the fact that only half of the neutrons goes in the right direction. The average fusion product mass $m_{F}$ is $3.3410^{-27} \mathrm{~kg}$ and the average $x$ momentum of a single fusion product particle is then $2.652 \cdot 10^{-20} \mathrm{~kg} \mathrm{~m} / \mathrm{s}$.

\section{Neutron absorption and fission product range}

The absorption of neutrons is modeled by the microscopic cross section $\sigma$. For the relevant materials, the most important effect after neutron absorption is nuclear fission. Nuclear interactions other than fission and neutron capture such as scattering are neglected as the respective cross sections are orders of magnitude smaller for the relevant materials and neutron energies, as will become clear later. The fraction $r_{\sigma}$ represents the number of fission reactions initiated per absorbed neutron. For an impinging neutron beam with intensity $I_{0}$ at the surface, the remaining intensity $I x$ at a depth $x$ is then:

$$
I_{x}=I_{0} e^{-N \cdot \sigma \cdot x}
$$

With $\mathrm{N}$ the atomic density of the medium (for uranium, $\mathrm{N}=0.048 \cdot 10^{24}$ atoms $/ \mathrm{cm}^{3}$ ).

The fission products are charged particles and are, alas, stopped relatively fast compared to neutrons. The approximate relationship between speed $v$ and distance $r$ for charged particles is:

$$
\frac{v}{v_{f i s s}}=1-\frac{r}{r_{m}}
$$

with $v_{\text {fiss }}$ the initial speed of the charged particle (about $1.2 \cdot 10^{7} \mathrm{~m} / \mathrm{s}$ ) [13] and $r_{\mathrm{m}}$ the range. According to [13], the range $r_{m}$ of fission fragments in $U$ is $0.66 \cdot 10^{-5} \mathrm{~m}$. 
Thus, in order not to waste too much fissionable material on the sail, it is necessary that most of the impinging neutrons are absorbed within the first few micrometers of the sail. If this turns out to be impossible as will become clear soon, it is advisable to make the fissionable material layer on the sail not thicker than a few micrometers anyway: a significant fraction of the neutrons will not be causing fission then, but at least no fissionable material (reaction mass) is wasted.

In figure 2, the absorption depth $(1 / \mathrm{N \sigma})$ of neutrons as a function of cross section is displayed. It can be seen that a cross section of over 1000 barn at the very least and preferably over 10000 barn is required for a significant fraction of neutrons to be absorbed in a layer of only a few micrometers thin.

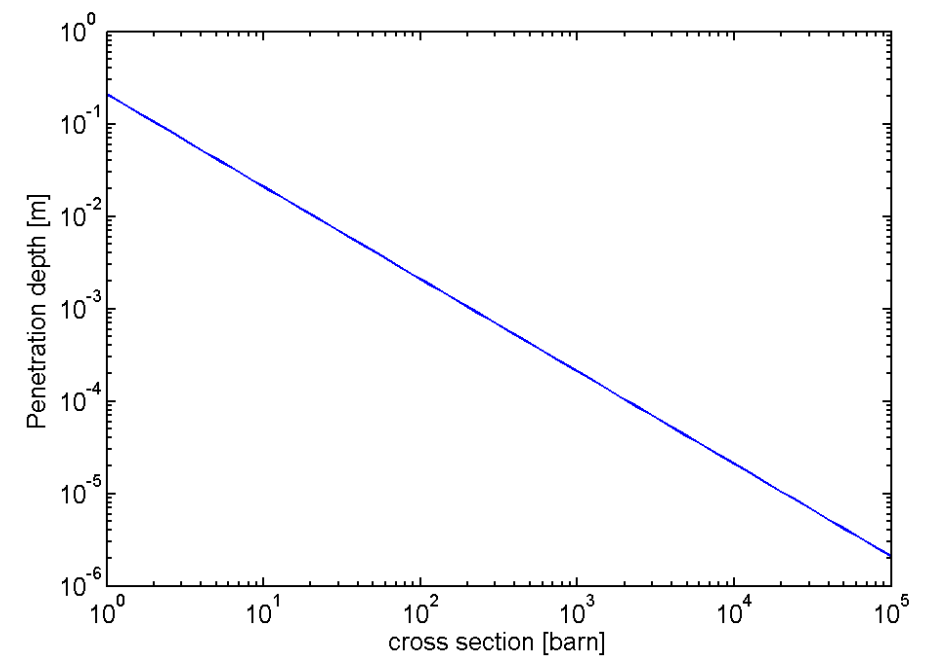

Figure 2: absorption depth (depth at which a fraction of 1/e of impinging neutrons is left) in uranium as a function of cross section

Such high cross sections can be obtained when using fissile materials $\left({ }^{235} \mathrm{U},{ }^{239} \mathrm{Pu}, \ldots\right)$ as illustrated in figure 3. Also, these materials also show negligible neutron scattering at these energies; their main mode of neutron interaction is fission. In the rest of this paper, we will therefore assume ${ }^{235} \mathrm{U}$ or ${ }^{239} \mathrm{Pu}$ as fissile material covering the sail. Other fissile materials are currently very scarce, though this could be changed in the future by setting up industrial scale production, as e.g. ${ }^{242 \mathrm{~m}} \mathrm{Am}$ can be bred in a fast reactor from ${ }^{241} \mathrm{Am}$ which is present in sizable amounts in spent nuclear fuel from light water reactors [14].

Furthermore, a second necessary condition is the use of very low-energy (cold) neutrons, having energies in the meV range. Thus, an important part of the propulsion system design will be a device to slow the fusion-generated fast neutrons down to low energy.

In current nuclear technology, a layer of cold deuterium or heavy water is used for this, of which the former is present as nuclear fusion fuel anyway in the rocket. An important parameter to consider is the efficiency $\eta_{n, m o d}$, i.e. the amount of cold neutrons exiting the moderation device for every fast neutron entering it. 




Figure 3: Fission cross-sections as a function of neutron energy [15].

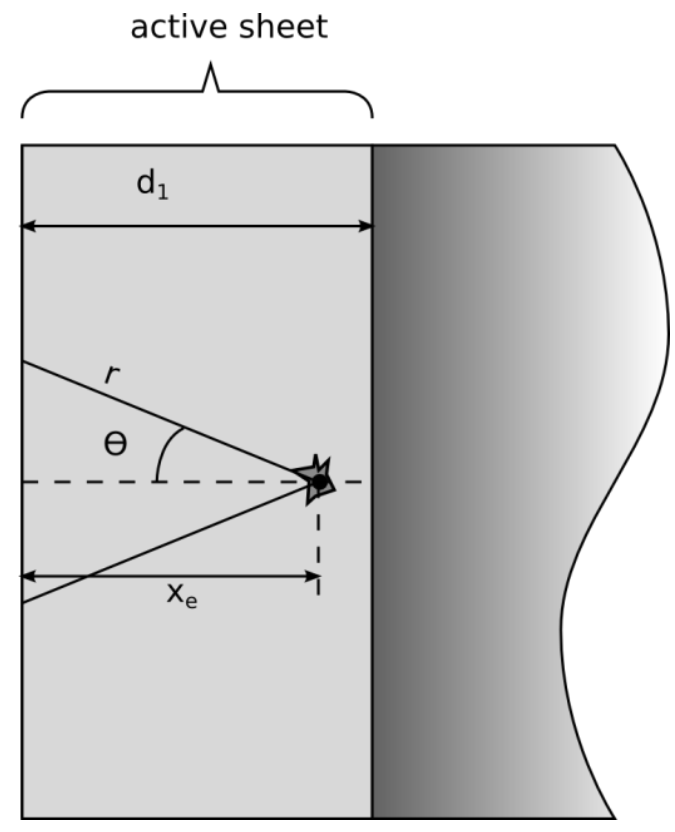

Figure 4: a schematic cross section view of the thrust sheet, with a fission even occurring at depth $\mathrm{x}_{\mathrm{e}}$, causing a fission product to be released under an angle $\theta$ (other fission product not shown).

\section{Exhaust speed calculation}

We will now calculate generated thrust per impinging neutron, with the fission cross section as most important parameter.

For fission products emitted at a depth $x_{e}\left(x_{e}<=r_{m}\right)$, the maximum angle $\theta_{m}$ (with respect to the normal to 
the sail) at which the particles will still reach the surface will be:

$$
\theta_{m}=\arccos \left(\frac{x_{e}}{r_{m}}\right)
$$

We will now calculate $\left\langle v_{\text {surf }}\right\rangle$, the average speed in the $x$ direction at the surface of the sail of a particle emitted at speed $v_{e}$ at depth $x_{e}$ between 0 and $d_{1}$, assuming semi-spherical isotropic distribution (figure 4). Note that two particles are always emitted in opposite directions. The second particle is always stopped by the sail, and is not included in the calculation below.

Integrating the $x$-axis projection of $v$ over the relevant surface $S$ (the intersection of the cone with apex angle $\Theta_{m}$ and a sphere with radius $\mathrm{x}$ ) and dividing by the surface area of a half sphere with radius $\mathrm{x}$ yields the average particle speed $v_{x, a v}(x)$ at the surface of the sail, for particles emitted at depth $x$.

$$
v_{x, a v}(x)=\frac{\oint_{\mathrm{S}} \mathrm{v}_{\mathrm{fiss}}\left(1-\frac{\mathrm{r}}{\mathrm{r}_{\mathrm{m}}}\right) \sin (\theta) \cos (\varphi) d S}{2 \pi \mathrm{x}^{2}}
$$

To obtain the average speed at the surface in the $x$ axis direction $\left\langle v_{\text {surf }}\right\rangle$, (4) is averaged with a weighting factor from equation (1) to account for nonuniform emission as a function of depth as the neutron flux and thus the fission rate is larger at the outside of the sail.

$$
<\mathrm{v}_{\text {surf }}>=\frac{\int_{0}^{\min \left(d_{1}, r_{m}\right)} v_{x, a v}(x) e^{-N \cdot \sigma \cdot x} d x}{\int_{0}^{\min \left(d_{1}, r_{m}\right)} e^{-N \cdot \sigma \cdot x} d x}
$$

As no analytical solution was found, these integrals were solved numerically using a Monte Carlo method. A random number generator was used to generate particles emitted at depth $x$. Using (2) and (3), the speed of those particles at the surface was calculated. An average was taken over 10000 particles. A weighted average with weighing factor (1) was then applied over a depth range $\left[0, d_{1}\right]$. The results are plotted in figure 5 . 


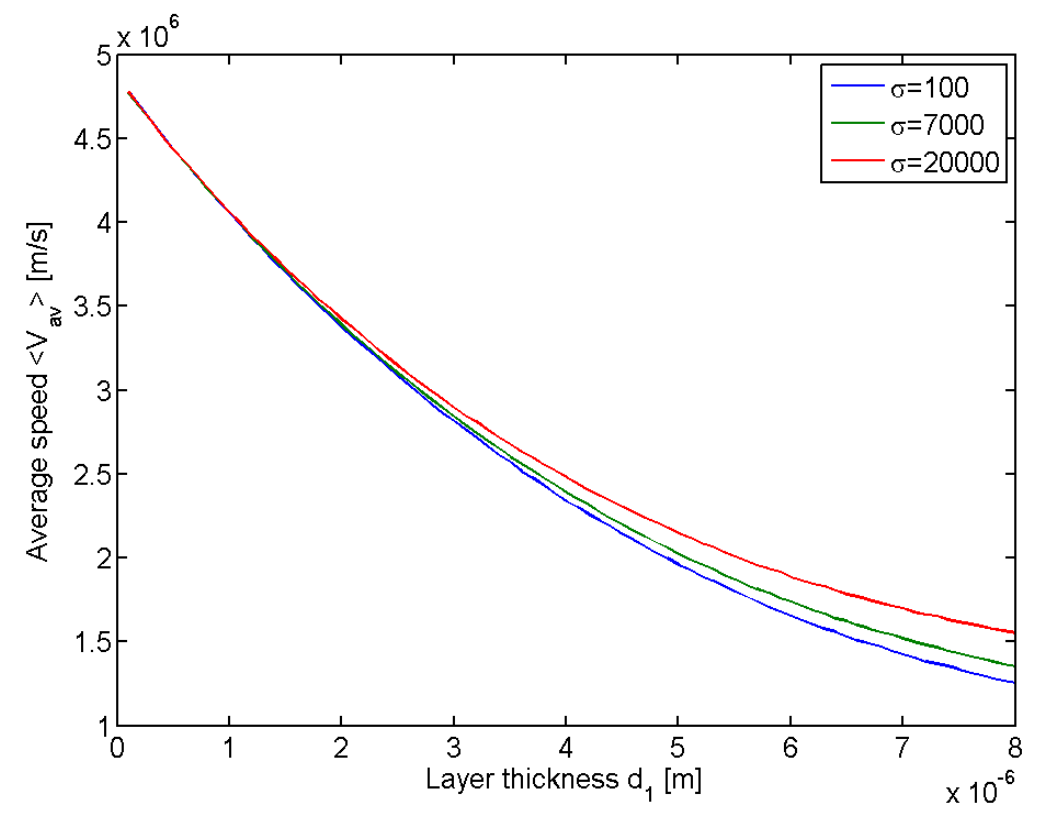

Figure 5: average $x$-axis speed of fission products at the surface of the sail, generated in a layer of thickness $d_{1}$.

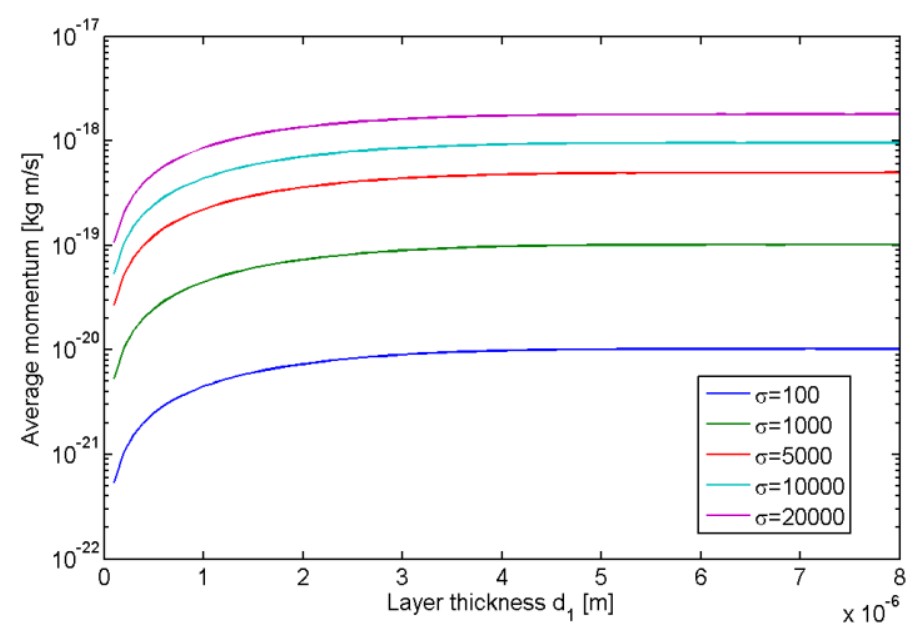

Figure 6: average $\mathrm{x}$-axis momentum produced per neutron impinging on a ${ }^{235} \mathrm{U}$ sail, with fission cross section $\sigma$ as parameter.

The average $\mathrm{x}$-axis momentum of a fission fragment at the surface can now also be calculated, based on an average fission particle mass $m_{\text {fiss }}$ of $118 \mathrm{Da}$.

At this point, it must be noted that not all absorbed neutrons cause fission. We therefore introduce a factor $r_{\sigma}$ to account for the fact that sometimes no fission reaction is initiated by neutron absorption, but an isotope 1 unit higher in atomic mass is generated instead. For ${ }^{235} U, r_{\sigma}$ equals 0.855 [16]. Upon neutron capture without fission, the low cross section isotope $U^{236}$ is generated, which does not react 
further (see section: sail regeneration). For ${ }^{239} \mathrm{Pu}, 23.5 \%$ of captured neutrons generate ${ }^{240} \mathrm{Pu}$, which then captures a second slow neutron to transmute to ${ }^{241} \mathrm{Pu}$, which has a fission cross section $35 \%$ higher than that of ${ }^{239} \mathrm{Pu}$ and a $73 \%$ fission probability. This translates into a need for 1.47 neutrons for 0.93 fission reactions, or $r_{\sigma}=0.6337$. Therefore, the performance of ${ }^{235} \mathrm{U}$ can be expected to be superior even though the fission cross section of ${ }^{239} \mathrm{Pu}$ is about $20 \%$ higher [17].

Furthermore, the average momentum produced per neutron impinging on the sail as a function of fission cross section (depending on neutron energy) and layer thickness can be calculated, by multiplying with the fraction $r_{\sigma}\left(1-e^{-N \cdot \sigma \cdot d_{1}}\right)$ of impinging neutrons used. The results are plotted in figure 6 . It can be seen that there is almost no rise in average momentum from a layer thickness of 3 micrometers on. For that layer thickness, the average particle speed at the surface is $0.94 \% \mathrm{c}$. This speed is only weakly dependent on $\sigma$. With higher $d_{1}$ there will only be extra consumption of fissile material without any benefit to thrust.

\section{Further performance calculations}

\subsection{Efficiency parameters}

We have already stated that a significant fraction of neutrons from the fusion reaction will get lost without having incited a fission reaction. We therefore define a neutron efficiency $\eta_{n}$ as the fraction of fusiongenerated neutrons that actually hits the sail. The neutron efficiency $\eta_{n}$ can be subdivided in geometrical effects (neutrons hitting the reactor wall, the sail only being located on one side of the ship etc.) and absorption in the neutron moderator between the fusion reactor and the sail:

$$
\eta_{n}=\eta_{n, \text { geom }} \cdot \eta_{n, \bmod }
$$

A reasonable estimation of the obtainable value for $\eta_{n \text {,geom }}$ is $1 / 3$, or 0.5 if neutron reflectors are used to deflect more neutrons to the sail. For $\eta_{n, \bmod }$, we estimate $43 \%$ as a realistic value discussed later leading to $a \eta_{n}$ of at least 0.144 . The loss due to non-complete absorption in the sail is not factored in, and will be included separately in the equations.

Likewise, not all charged fusion particles generated will be expelled from the rocket along the axis of flight before significant thermalization or other loss has occurred. This is not always recognized in work about future starship propulsion, where all too easy the full speed of the fission fragments or fusion products straight from the reaction that produced them is put in the rocket equation. We therefore define also a fusion particle emission efficiency $\eta_{F} . \eta_{F}$ is the fraction of the momentum of the fusion products that can potentially be generated with a certain quantity of fuel that is actually used for thrust. It not only models the efficiency of the magnetic nozzle, but also includes all other effects that reduce the momentum delivered by the rocket such as the need for converting of some of the energy into electricity to power the ship or the fractional burnup of fusion fuel.

Another factor to consider is the additional system mass (i.e. excluding fuel) that adding a fission thrust sail will impart on the ship. This mass arises from e.g. the fact that the fuel tanks have to be placed at a larger distance in order to make the reactor more open for neutrons to escape and reach the sail, the additional auxiliary system, the mass of the inert part of the sail, etc.

Due to the simplicity of the thrust sail system, the additional mass is expected to be low: as already stated the neutron moderator - which can be expected to be one of the heavier components of the thrust sail system - can use the same deuterium as is present as fusion fuel anyway.

Furthermore, a less powerful fusion reactor will be required to reach the same acceleration (also entailing less powerful heat radiators), and less deuterium fuel with therefore a smaller cryogenic storage system for this low-density liquid is required for reaching the same delta-v. 
The relative change in dry mass caused by adding the fission sail is modeled as mass factor $r_{\text {mass }}$.

The factors, $\eta_{n}, \eta_{F}$ and $r_{\text {mass }}$ will determine whether or not the addition of the thrust sail is sensible.

\subsection{Estimation of $\eta_{n}$}

We will now model neutron moderation and estimate $\eta_{n}$. For a first-order estimation, the following data (table 2) are used:

\begin{tabular}{|l|l|}
\hline Deuterium scatter crossection $\sigma_{\mathrm{D}, \mathrm{s}}[26][27]$ & 3.5 barn (average in range $[0.1 \mathrm{eV}, 1 \mathrm{MeV}]$ ) \\
\hline Deuterium capture crossection $\sigma_{\mathrm{D}, \mathrm{c}}[29]$ & 0.000519 barn (thermal) \\
\hline Liquid deuterium atom density $\left[\mathrm{cm}^{-3}\right]$ & $4.25 \cdot 10^{22}$ \\
\hline $\begin{array}{l}\text { Logarithmic neutron energy reduction factor } \\
\text { per collision }\end{array}$ & $\xi=\ln \left(\frac{\mathrm{E}_{0}}{\mathrm{E}_{1}}\right)=1-\frac{(A-1)^{2}}{2 A} \ln \left(\frac{A+1}{A-1}\right)=0.696$ \\
\hline
\end{tabular}

Table 2: nuclear diffusion data

From this the macroscopic scattering and capture cross sections are calculated: $\Sigma_{D, S}=0.15 \mathrm{~cm}^{-1}$ and $\Sigma_{D, c}$ $=2.2 \cdot 10^{-4} \mathrm{~cm}^{-1}$. For a given material, the mean free paths of those phenomena scale as the inverse of the cross section.

To reduce the neutron from $\mathrm{MeV}$ to meV speeds, about 31 collisions are needed. The average total path traveled is thus $31 / \Sigma_{D, S}=207 \mathrm{~cm}$. This causes a loss of $\left(1-e^{-207 \cdot \Sigma_{D, c}}\right)=5 \%$, i.e. an $\eta_{\mathrm{n}, \bmod }$ of $95 \%$.

For a more accurate estimation of moderator performance which included neutron backscattering out of the moderator and takes the lower capture cross sections at higher neutron energy into account, a Monte Carlo simulation was employed. The main simplifying assumptions employed were:

1. The use of energy-dependent scatter cross sections from [26] (figure 7).

2. The use of energy-dependent capture cross sections from [26] (figure 7).

3. An exponential distribution of travel distance between collisions with factor $\Sigma_{\mathrm{D}, \mathrm{S}}$.

4. A uniform distribution of scattering angle in an interval $[-\pi / 2, \pi / 2]$.

5. A reduction of speed at every collision by a factor $\mu=0.7$ until thermal equilibrium is reached, thereafter speed is constant.

6. An exponential distribution of neutron loss distance with factor $\Sigma_{\mathrm{D}, \mathrm{c}}$

7. Incoming neutron speeds according to table 1.

Note that the interval in distribution used in assumption (4) was observed not to influence efficiency for more than $3 \%$ when changed from $[-\pi / 3, \pi / 3]$ to $[-\pi / 2, \pi / 2]$. The needed moderator thickness did almost double though. Therefore, we have confidence in the employed method when it comes to efficiency calculations. For a final design, a more careful study is required. 
The simulation results are plotted in figure 8 . It can be seen that in order to reach a median neutron energy of $1 \mathrm{meV}$ range corresponding to a ${ }^{235} \mathrm{U}$ fission cross section of about 3000 [28], a liquid deuterium moderator layer of 1.04 meter thickness is needed. The efficiency $\eta_{n \text {, mod }}$ is then $43 \%$.

Assuming the moderator can be placed in the configuration of a third of a 5 meters radius sphere (similar to the size of the National Ignition Facility's target chamber, which yields in the preliminary design proposed in the later sections of this work a much more conservative power per reactor volume than in the Daedalus design [4]) around the center of the fusion reactor, the mass of the liquid deuterium (170 $\mathrm{kg} / \mathrm{m}^{3}$ at $20 \mathrm{~K}$ ) needed would be 18.5 tons. Note again that this 'dead volume' of deuterium can be used as fusion fuel once the fission fuel has been used up.



Figure 7: Cross sections used in Monte Carlo model. Plot based on data from [26].
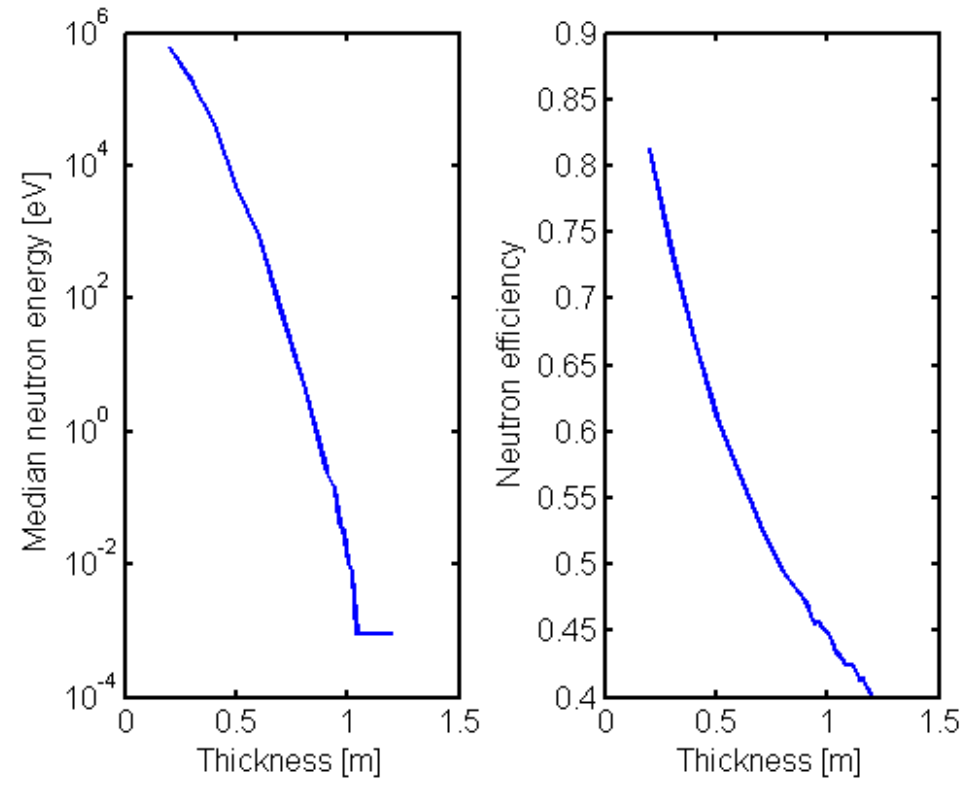
Figure 8: Monte Carlo simulation results, showing median neutron energy and efficiency versus moderator thickness.

\subsection{Delta-v}

The delta-v for a pure fusion based propulsion system is simply given by the rocket equation:

$$
\Delta \mathrm{v}_{\mathrm{F}}=\eta_{F} \cdot v_{F} \cdot \ln \left(\frac{M_{D}+M_{\text {empty }}}{M_{\text {empty }}}\right)
$$

with $M_{D}$ the mass of the deuterium fuel and $M_{\text {empty }}$ the mass of the rocket with empty fuel tanks.

To calculate the contribution of adding a fission thrust sail, one must consider that:

- for every 5 fusion product particles, only 2 neutrons are produced

- the neutron efficiency $\eta_{\mathrm{n}}$ and the factor $r_{\sigma}\left(1-e^{-N \cdot \sigma \cdot d_{1}}\right)$ further limit the amount of used neutrons

- one of the two fission products always gets stuck in the sail, which was not factored in so far.

- a mass weighted average should be taken of the speed of the different particles

- adding the sail causes a change in dry mass as discussed above, modeled by the mass factor $r_{\text {mass. }}$

Plugging this in the rocket equation leads to a delta- $v$ for a propulsion system with added sail of:

$\Delta v_{\text {sail }}=\frac{\frac{2}{5} \mathrm{~m}_{\mathrm{fiss}} \eta_{\mathrm{n}} r_{\sigma}\left(1-e^{-N \cdot \sigma \cdot d_{1}}\right)<\mathrm{v}_{\text {surf }}>+\mathrm{m}_{\mathrm{F}} \eta_{\mathrm{F}} \mathrm{v}_{\mathrm{F}}}{\frac{4}{5} \mathrm{~m}_{\mathrm{fiss}} \eta_{\mathrm{n}} r_{\sigma}\left(1-e^{-N \cdot \sigma \cdot d_{1}}\right)+\mathrm{m}_{\mathrm{F}}} \ln \left(\frac{M_{\text {fiss }}+M_{D}+r_{\text {mass }} \cdot M_{\text {empty }}}{r_{\text {mass }} \cdot M_{\text {empty }}}\right)$

Note that there is no $\eta_{F}$ in the denominator as this is a velocity (or impulse) ratio and not a mass ratio. The change in initial acceleration of the rocket when adding the fission sail is now calculated.

The total mass of fissile elements $M_{\text {fiss }}$ that has to be carried next to the deuterium fuel mass $M_{D}$ is now calculated. For every deuterium atom used as fuel, the number of reacting fissionable elements is $\frac{2}{5} \eta_{\mathrm{n}}\left(1-e^{-N \cdot \sigma \cdot d_{1}}\right)$

Therefore,

$$
M_{\text {fiss }}=2 / 5 \eta_{n}\left(1-e^{-N \cdot \sigma \cdot d_{1}}\right) \frac{\mathrm{m}_{\text {fissile }}}{\mathrm{m}_{\mathrm{D}}} M_{D}
$$

with the atom mass ratio $\frac{m_{\text {fissile }}}{m_{D}}$ equal to 119.5 for ${ }^{239} \mathrm{Pu}$ and deuterium and 117.5 for ${ }^{235} \mathrm{U}$ and deuterium.

The weight change of the empty rocket when adding the sail system is modeled again with the mass factor $r_{\text {mass }}$. 
The rocket's acceleration at start scales with a factor $r_{\mathrm{a}}$ :

$\mathrm{r}_{\mathrm{a}}=\frac{\mathrm{a}_{\text {fission }}}{a_{F}}=\frac{I_{\text {fiss }}}{M_{\text {tot }, \text { fiss }}} \frac{M_{\text {tot }, F}}{I_{F}}$

(10)

with $\mathrm{I}_{\text {fiss }}$ and $\mathrm{I}_{\mathrm{F}}$ the sum of the $\mathrm{x}$-axis momenta of the released particles per deuteron in case of an added fission sail and pure fusion respectively, and $M_{\text {tot,fiss }}$ and $M_{t o t, F}$ the total ship mass in the two cases.

From Table 1:

$$
I_{F}=\frac{\eta_{F}}{5} \sum(\text { fusion particle momenta in } x)
$$

In which the momenta of the noncharged particles are multiplied by $2 / \pi^{2}$ in order to account for their nondirectionality. Furthermore,

$$
I_{f i s s}=\frac{2}{5} \eta_{n}\left(1-\mathrm{e}^{-\mathrm{N} \cdot \sigma \cdot \mathrm{d}_{1}}\right) r_{\sigma} m_{\text {fiss }}<\mathrm{v}_{\text {surf }}>+\mathrm{I}_{\mathrm{F}}
$$

The fraction of total masses of a fission sail-boosted and a pure-fusion rocket is:

$$
\frac{\mathrm{M}_{\mathrm{tot}, \mathrm{fiss}}}{\mathrm{M}_{\mathrm{tot}, \mathrm{F}}}=\frac{M_{\text {fiss }}+M_{D}+r_{\text {mass }} \cdot M_{\text {empty }}}{M_{D}+M_{\text {empty }}}
$$

To calculate the acceleration at the end of the boost phase, this ratio simply needs to be replaced by $r_{\text {mass. }}$.

\subsection{Performance estimation}

In the following section, a first performance estimation is made for a series of typical parameters. For the pure fusion case a ship with $M_{\text {empty }}$ equal to 1000 tonnes is assumed, with a mass ratio $\left(M_{D}+M_{\text {empty }}\right)$ / $M_{\text {empty }}$ of 15 (Project Daedalus assumed a mass ratio of about 13.5 [4]). In order to assess the performance of adding the fission sail, the equations above are solved for the following parameters:

\begin{tabular}{|l|l|}
\hline$r_{\text {mass }}$ & $1,1.1,1.2$ \\
\hline$\left(\sigma[\right.$ barn] $\left.], \eta_{n}, r_{\sigma}\right)$ & $(3000,0.144,0.855)$, \\
& $(3000,0.216,0.855)$, \\
& $(3600,0,216,0.6337)$ \\
\hline$d_{1}[m]$ & $3 \cdot 10^{-6}$ \\
\hline
\end{tabular}

Table 3: parameters used for calculating figures 9-10

The lower cross sections are not evaluated with lower $\eta_{n}$ as they occur with thermal neutrons for which $\eta_{n}$ is higher. $\eta_{\mathrm{F}}$ is taken as variable and swept between 0 and 1 , as no concrete data about its likely value is known to us at this time.

The results are plotted in figures 9 and 10. The most important conclusion is that, in a range of reasonable values for the fission sail parameters and assuming a neutral effect of adding the sail on the ships dry mass $\left(r_{\text {mass }}=1\right)$, adding the system would make sense when the efficiency of the fusion system 
$\eta_{F}$ is below the range [0.31 0.38]. Below that range, the $\Delta v$ improvement offered can be several hundreds of percents. Even if $r_{\text {mass }}$ is raised to 1.2, adding the sail still makes sense for a $\eta_{F}$ below 0.21 .

Acceleration improvement becomes significant below an $\eta_{F}$ of about 0.38 for a $r_{\text {mass }}$ of 1 . Even if there is a $20 \%$ dry mass penalty on adding the sail $\left(r_{\text {mass }}=1.2\right)$, the fission sail is still beneficial for $\eta_{F}$ below 0.21 .

For an $\eta_{F}$ below 0.1 , the improvement can be a factor $30 \%$ or more, significantly influencing mission design.
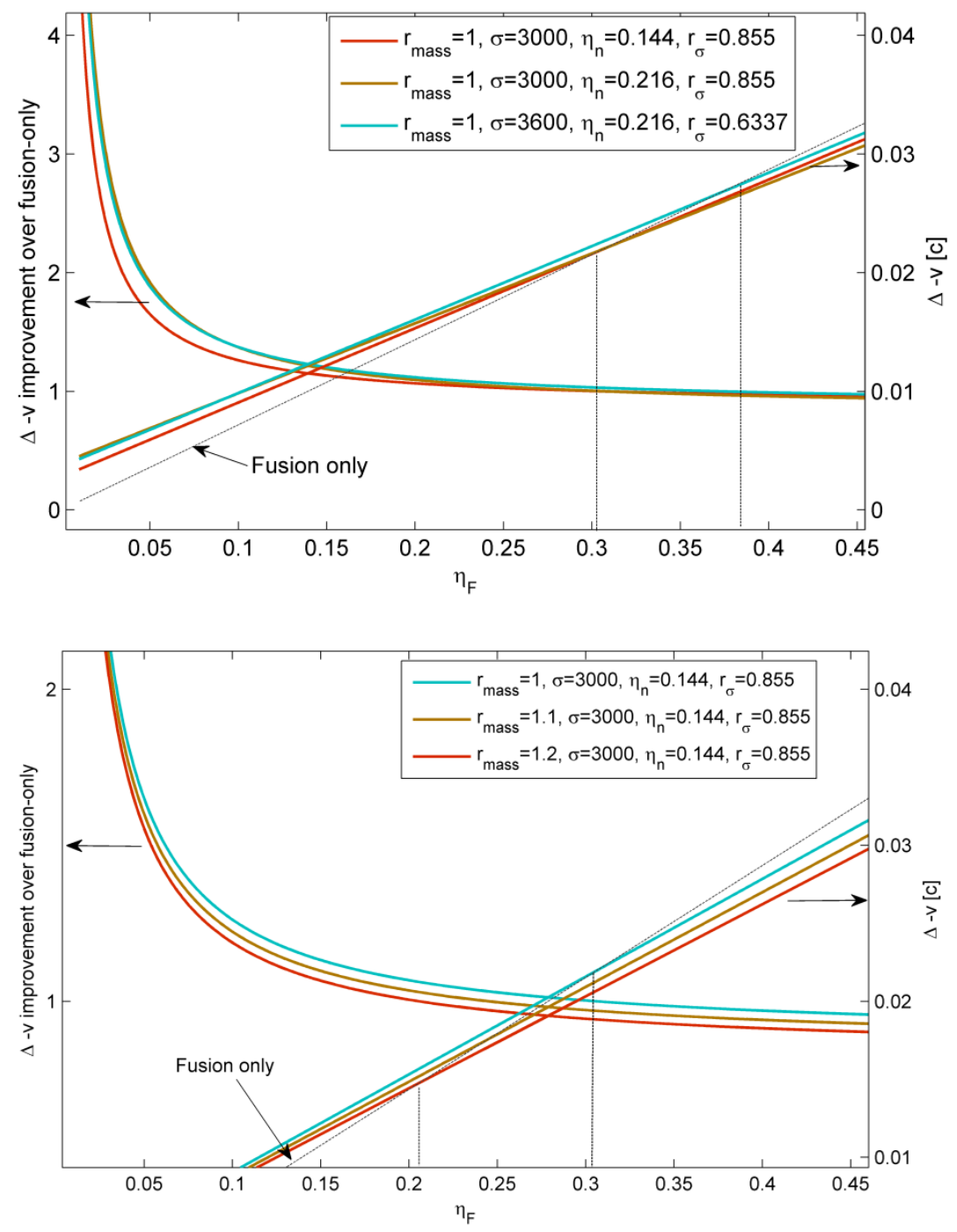

Figure 9: Calculated delta-v improvement factors and absolute delta-vs for a number of cases. The cases with $\sigma=3000$ are for ${ }^{235} \mathrm{U}$, when $\sigma$ equals 3600 the fissile material used is ${ }^{239} \mathrm{Pu}$. 




Figure 10: acceleration improvement offered by addition of fission sail, showing the average of the improvement at start and the improvement at the time when almost out of fuel.

\section{Further system design}

In this section, additional engineering considerations and first-order calculations are presented with the intention of making the rather abstract view presented in the earlier sections more concrete. This is not a full, optimized rocket design but rather a first exercise to see if the sail booster concept might make sense in practice. Topics such as sail design and thermal considerations are covered. A conceptual example design is given, which leads to an estimation of $r_{\text {mass. }}$.

\subsection{Sail regeneration}

The low thickness of fissile material allowed on the sail means the layer will be used up relatively quickly, and the thickness will soon diverge from the designed optimal thickness. Also, fission products will accumulate in the sail. It is possible though to dynamically keep the layer thickness at the optimal value by projecting new material from the ship, e.g. using an thermal evaporation source located on the main structure of the ship.

This periodic replenishment of the fission material layer can be preceded by a step in which the sail is heated, boiling off the trapped fission products still present. For this reason we will assume the fission products generated and trapped in the sail do not contribute to $\mathrm{M}_{\mathrm{empty}}$. Of course, in that case the fission sail's structural material should have a higher melting point than that of common fission products. Also, do note that the fissile layer of a 500 by 500 meter sail coated with $3 \mu \mathrm{m}$ of uranium already weighs 14 tons. Thus, these coating cycles will be relatively sparsely spaced in time. In the example design discussed in section 6.6, less then 200 recoating cycles are needed over the entire mission duration. 
Another advantage of employing sail regeneration is that the radioactive fissile layer can be applied to the sail in space, after ship assembly, thus contributing to safety. Furthermore, the high temperature resistant back layer of the sail could be manufactured in a similar way, by evaporating it on a more classic material such as polyimide, used in solar sails. As a side note, a further advantage of the sail would be a dual use as micrometeorite shield as discussed in the appendix.

\subsection{Thermal load on the sail}

The thermal load caused by cold neutrons to the sail is negligible. However, the fast fission reaction products generated by the neutrons do deposit a large part of their kinetic energy in the sail. From figure 5 , it can be seen that for a 3 micrometer thick fissile layer (the worst case) about $7 / 8$ of the kinetic energy is left in the sail, amounting to about $148 \mathrm{MeV}$. This amounts to $2.36 \cdot 10^{-11} \mathrm{~J}$ per fission reaction.

The heat loss of the sail by radiation, $P_{\text {rad }}$, is given by Stefan-Boltzmann's law:

$$
P_{\text {rad }}=2 \cdot A \cdot \sigma_{S} \cdot \varepsilon \cdot T^{4}
$$

With $A$ the surface area (and the factor 2 for double-sided emission), $T$ the temperature, $\sigma_{\mathrm{s}}$ StefanBoltzmann's constant $\left(5.67^{-1} 10^{-8} \mathrm{~J} \mathrm{~s}^{-1} \mathrm{~m}^{-2} \mathrm{~K}^{-4}\right.$; and $\varepsilon$ the emissivity of the surface (assumed to be 0.9$)$.

Of course there will be a temperature limit for the sail, which will impose a limit on the sail's maximum power per unit of area. This forms a design constraint: next to structural weakening of the sail's structure, the unwanted evaporation [30] of fissile material back from the sail should be taken into account in the design. This could be a reason to select uranium oxide instead of pure uranium as material for the sail, which has a melting temperature of $2827^{\circ} \mathrm{C}$ instead of $1408^{\circ} \mathrm{C}$. Of course, then the energy needed for sail regeneration as discussed above will increase too.

As an example, we assume a fusion reactor generating $10 \mathrm{GW}$ of fusion power. $2.6 \cdot 10^{21}$ reactions involving $5 \mathrm{D}$ atoms will then occur per second. Using a neutron efficiency $\eta_{\mathrm{n}}$ of 0.17 (assuming $\eta_{\mathrm{n} \text {,mod }}$ to be 0.42 as calculated above and $\eta_{n \text {,geom }} 0.4$, a compromise between the values of $1 / 3$ and 0.5 discussed above), $8.8 \cdot 10^{20}$ neutrons will be slowed down to cold temperatures and reach the ${ }^{235} \mathrm{U}$ coated sail every second. Of these neutrons, with a 3 micron thick fissile layer and a $\sigma$ of 3000 barn, $4.2 \%$ will be used of which a fraction $r_{\sigma}$ equal to 0.855 incites fission.

At $148 \mathrm{MeV}$ per fission reaction this would put a thermal load of $759 \mathrm{MW}$ on the sail. Thus, a sail $150 \mathrm{~m}$ in radius will reach a temperature of $570 \mathrm{~K}$, which is well below the melting temperature of uranium, according to equation (14). The more general relation is plotted in figure 11, showing that sail radii under $1 \mathrm{~km}$ suffice for fusion powers up to TW levels.

It should be noted that these numbers imply that the ship should be shielded from thermal radiation from the sail, e.g. by a high temperature version of multilayer insulation foil used in present-day satellites. Yet another concern is heating of the sail by heat flux from the fusion reactor's radiators (figure 1, part $D$ ). During design, care must be taken to limit this flux as well. 


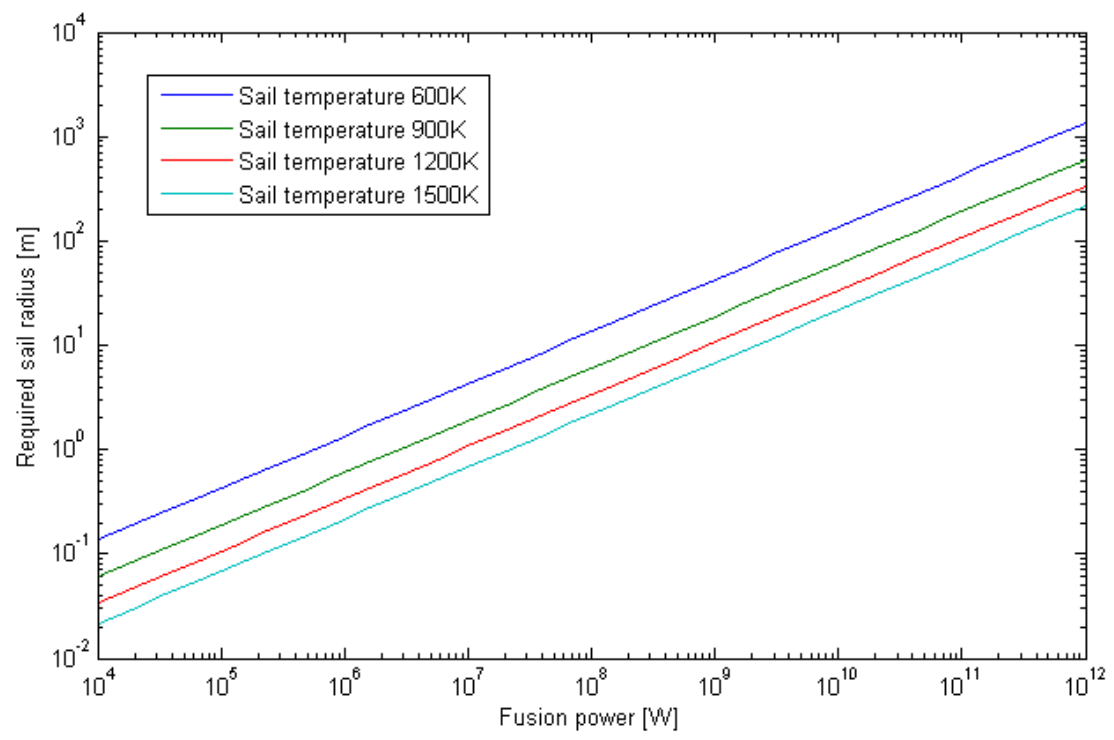

Figure 11: Required sail radius for a certain fusion reactor power, assuming a $\sigma$ of 3000 barn, a $\eta_{n}$ of 0.17 and a 3 micron thick fissile material layer on the sail.

\subsection{Thermal load on the moderator.}

The fast neutrons originating from the reactor need to be slowed down to very low speeds by the moderator, which causes a significant thermal load here as well.

A first remark here is that in the fusion-only design, the thermal load caused by these neutrons will be about as significant as for the fission sail boosted case, as neutron shielding will be present anyway to protect the ship from the neutron flux and to convert some of the captured neutron momentum into useful thrust.

However, it can be further remarked here that in the fusion-only case there is no need to keep a moderator at cryogenic temperatures, thus facilitating heat removal. To alleviate this disadvantage of the sail booster a multilayer moderator could be employed, e.g. having one $600 \mathrm{~K}$ warm layer followed by a second layer at a cryogenic temperature. If the first layer is designed to perform the major part of neutron thermalization, the thermal load to the second layer can be negligible.

To continue the example with the $10 \mathrm{GW}$ fusion reactor, it is clear from table 1 that $69.3 \%$ of the fusion energy is in neutron kinetic energy. About $50 \%$ of neutrons will fly off into space, while the other half gets captured by the moderator or by neutron shielding. Thus, the neutron load will be $3460 \mathrm{MW}$, which necessitates $0.26 \mathrm{~km}^{2}$ of two-sided radiators at a temperature of $600 \mathrm{~K}$ according to equation 14 . In the example design (section 6.5), another efficiency factor (thermal efficiency $\eta_{T}$ ) is introduced to model the thermal load imposed on the rocket for each watt of fusion energy produced by the reactor. Next to the neutron load, this also includes generated $\mathrm{x}$-rays, induced currents etc.

\subsection{Radiator mass}

As the rocket will need heat radiators as introduced above, it is necessary to look at the weight constraints imposed by such radiators. We will both consider solid, Tube-and-fin or heat pipe based radiator panes as well as possible more advanced concepts such as liquid droplet radiators. For the former, a weight of $5 \mathrm{~kg} / \mathrm{m}^{2}$ seems realistic, while the latter could reach values of about $1 \mathrm{~kg} / \mathrm{m}^{2}$ [31][32]. It should be remarked that the mass of solid radiators is determined by requirements to limit the chance of 
puncture by micrometeorites [33]. As the fission sail can act as a micrometeorite shield, a lower mass per area could be possible here. Equation (14) has been plotted in figure 12. It can be seen that, in order to radiate $1 \mathrm{GW}$, a $5000 \mathrm{~m}^{2}$ radiator working at $1200 \mathrm{~K}$ is needed. This radiator would weigh between 5 and 25 tons.

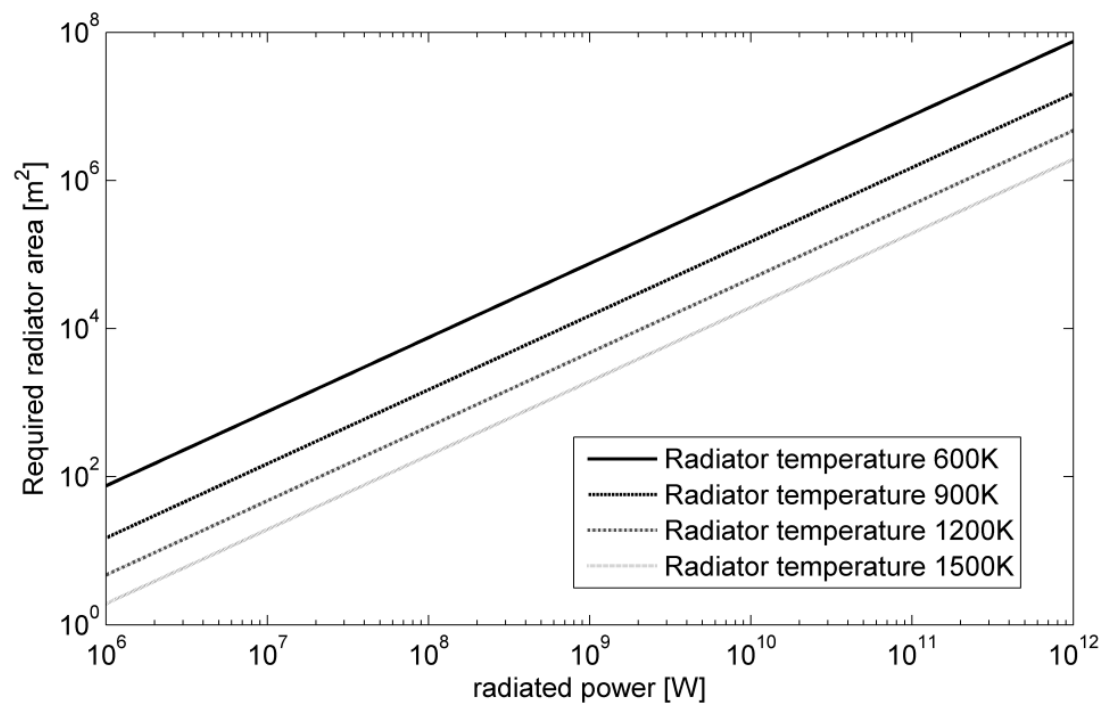

Figure 12: required radiator area for a certain thermal load, for various radiator temperatures

\subsection{Preliminary design of sail structure}

For structural strength calculations, we assume the sail to be a simply supported, uniformly loaded circular plate, for which the following relations have been proven [35]:

$$
\begin{aligned}
& \frac{q a^{4}}{E t^{4}}=K_{1} \frac{y}{t}+K_{2}\left(\frac{y}{t}\right)^{3} \\
& \frac{\sigma a^{2}}{E t^{2}}=K_{3} \frac{y}{t}+K_{4}\left(\frac{y}{t}\right)^{3}
\end{aligned}
$$

With $\mathrm{K}_{1}=1.016 /(1-\mathrm{v}), \mathrm{K}_{2}=0.376, \mathrm{~K}_{3}=1.238 /(1-\mathrm{v}), \mathrm{K}_{4}=0.294, v$ the Poisson ratio, $\mathrm{E}$ the Young's modulus, $t$ the plate thickness, $a$ the radius of the plate, $q$ the applied pressure, $y$ the maximum deflection and $\sigma$ the maximum stress due to flexure and diaphragm tension combined.

In designing the sail, a minimum thickness is imposed by the penetration depth of charged fission products in the sail. As explained around equation (2), a thickness in the order of 10 microns suffices for this. Furthermore, the sail should be a high temperature material. As a preliminary choice, tungsten is selected. For the corresponding material properties $\left(E=300 \mathrm{GPa}, v=0.28, \rho=19300 \mathrm{~kg} / \mathrm{m}^{3}\right.$, yield stress $\sigma_{\text {yield }}=750 \mathrm{MPa}$ ), the maximum total force a sail of $150 \mathrm{~m}$ radius can tolerate before breaking according to equations 15 and 16 has been calculated and plotted in figure 13 as a function of sail thickness. It is clear that the pressure even a minimum thickness sail can tolerate is significantly above that caused by the expected thrust of the example design (section 6.6) and of more powerful designs.

The weight of the uncoated sail is shown as well as a function of thickness. The weight of a $150 \mathrm{~m}$ radius, 8 micron thick sail is 11 tons. As a safety margin, the fissionable material coating of the sail is not assumed to contribute anything to the sail's strength. 

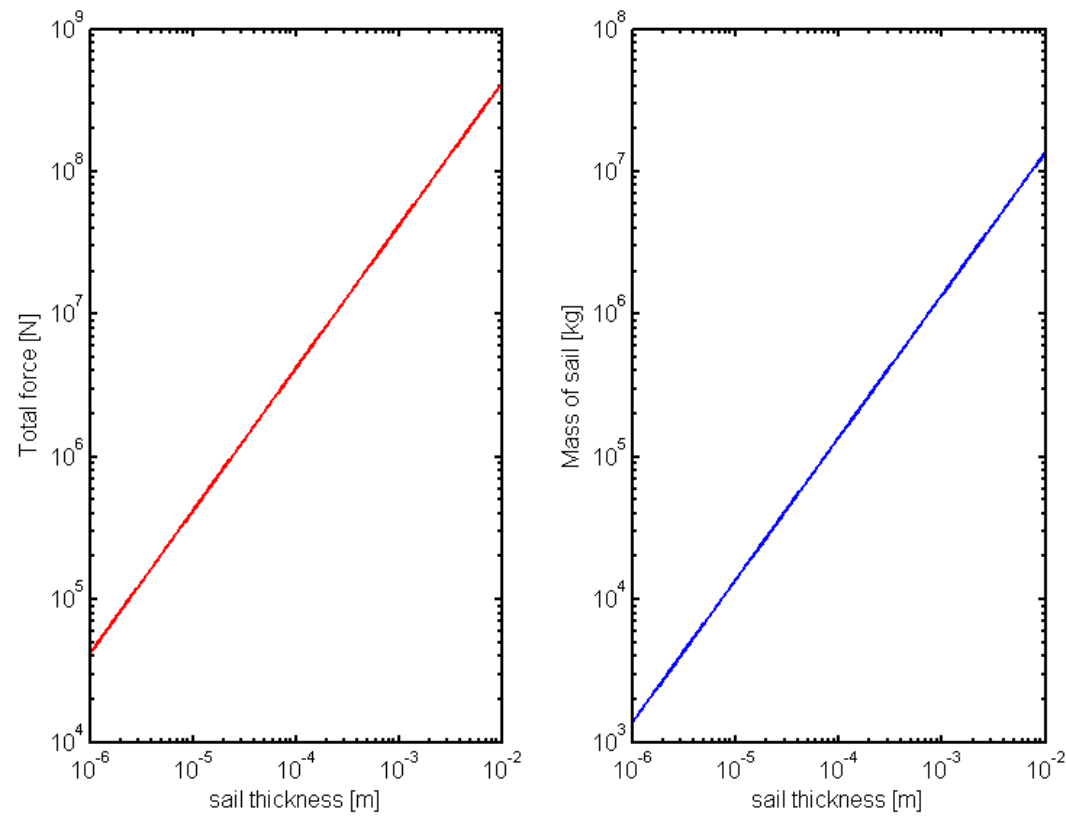

Figure 13: maximum total force a tungsten sail of $150 \mathrm{~m}$ radius can tolerate and the corresponding sail mass as a function of its thickness.

To the sail mass, the mass of the cables attaching it to the main structure should be added. In what follows, we assume the sail covers a solid angle 1/3th of a sphere (i.e. an in-plane angle $\theta_{\text {sail }}$ of $70.5^{\circ}$ ) as seen from the fusion reactor neutron source. The total force on the cables equals the sail thrust $F_{\text {sail }}$ divided by $\cos \left(\theta_{\text {sail }}\right)$. This is a worst case assumption, as not all cables need to be attached to the outer rim of the sail. The minimum cable cross section (all cables combined) is then $A_{\text {cable }}=F_{\text {sail }} / \sigma_{\text {yield }}$. $\cos \left(\theta_{\text {sail }}\right)$ and the total cable mass $\rho^{\prime} \mathrm{L}_{\text {cable }} \cdot \mathrm{A}_{\text {cable. }}$. As an example, with a sail radius of $150 \mathrm{~m}$, a cable length $\mathrm{L}_{\text {cable }}$ of $159 \mathrm{~m}$ and total force $\mathrm{F}_{\text {sail }}$ of $10^{4} \mathrm{~N}$, and assuming tungsten cables, the extra mass is 122 $\mathrm{kg}$. In the example design below, we assume an extra mass of 5 tons to cover the mass of cables, sail deployment apparatus and regeneration system.

Similar to solar sails, it could be that rotating the sail will be required to generate enough radial forces to avoid collapse [36] if the sail is not stiff enough from itself.

\subsection{Preliminary system design.}

The considerations above will now be used in a rough preliminary rocket design, intended to investigate if the fission sail concept could make sense in practice. The design will be for a relatively small probe, such as in Project Longshot. Mass estimations of components such as the fusion reactor and payload are taken from that project's report [34] and have been summarized in table 4. As Longshot was based on ${ }^{3} \mathrm{He}$ and not D-D fusion, radiators have been added as well as different efficiency figures as discussed. A higher mass ratio of around 12 has been assumed.

\begin{tabular}{|l|l|}
\hline Chamber [tons] & 4.35 \\
\hline Coil [tons] & 10.2 \\
\hline Igniter [tons] & 17.5 \\
\hline Fuel tanks[tons] & 55 \\
\hline Straps [tons] & 9 \\
\hline
\end{tabular}




\begin{tabular}{|l|l|}
\hline Center section [tons] & 2 \\
\hline Other [tons] & 4 \\
\hline Reactor [tons] & 10 \\
\hline Instruments [tons] & 3 \\
\hline Lasers [tons] & 2 \\
\hline Misc [tons] & 15 \\
\hline TOTAL [tons] & 132 \\
\hline
\end{tabular}

Table 4: project Longshot's system dry mass breakdown

The most important conclusion from the calculations is that a $r_{\text {mass }}$ factor of around 1.1 is realistic, which leads to the conclusion that if $\eta_{F}$ is indeed relatively low in a future D-D fusion propelled ship, adding the fission sail would make sense to improve performance. The considerations of this section lead to the system design summarized in table 5 , which shows the preliminary design of a small relatively low-power, relatively low $\eta_{F}$ rocket with or without fission sail. In the example design, the $\Delta v$ improvement is $13.6 \%$. A spreadsheet automating the design calculations is added as supplementary data, allowing the user to quickly estimate the effect of certain design decisions.

\begin{tabular}{|c|c|c|c|}
\hline Total fusion power [W] & $1.00 \mathrm{E} 10$ & Mass of sail utilities and cables [kg] & $5 \mathrm{E} 3$ \\
\hline Fusion efficiency $\eta_{F}$ & 0.14 & Mass of sail backplane $[\mathrm{kg}]$ & 10.3E3 \\
\hline Neutron efficiency $\eta_{n}$ & 0.17 & Total radiator mass [kg] & 4E4 \\
\hline Thermal efficiency $\eta_{T}$ & 0.6 & $\mathrm{M}_{\mathrm{fiss}}{ }^{235} \mathrm{U}[\mathrm{kg}]$ & $6.76 \mathrm{E} 05$ \\
\hline Neutron cross section $\left[\mathrm{m}^{2}\right]$ & $3.00 \mathrm{E}-25$ & Number of recoating cycles & 167 \\
\hline$r_{\sigma}$ & 0.855 & Delta-v fusion [\%c] & 0.94 \\
\hline Sail radius [m] & 150 & Delta-v with fission sail booster [\%c] & 1.07 \\
\hline Sail supporting layer thickness [m] & $8 \mathrm{E}-6$ & Relative improvement in Delta-v [\%] & 13.6 \\
\hline Fissile layer thickness on sail [m] & $3 \mathrm{E}-6$ & Accell. improvement by sail at end [\%]: & 24.9 \\
\hline Radiator mass per $\mathrm{m}^{2}[\mathrm{~kg}]$ & 2 & Sail heating [W] & 7.59E08 \\
\hline Radiator power per area $\left[\mathrm{W} / \mathrm{m}^{2}\right]$ & $2 \mathrm{E} 5$ & Sail temperature $[\mathrm{K}]$ & 569.6 \\
\hline Sail thermal emissivity & 0.9 & Mass ratio without sail & 12.6 \\
\hline Fusion fuel total mass $M_{D}[\mathrm{~kg}]$ & 2E6 & Mass ratio with sail & 15.2 \\
\hline Dry mass, without sail or radiators [k & 132E3 & $r_{\text {mass }}$ & 1.092 \\
\hline
\end{tabular}

Table 5: parameters and results of preliminary design exercise

\section{Discussion}

\subsection{Technical advantages}

Besides increasing the delta-v under the conditions mentioned, there are other advantages offered by the fission sail booster. As the acceleration increases, a mission designed for a certain acceleration could do with a much smaller fusion reactor, and thus smaller heat radiators and cryogenic fuel tanks, improving the mass ratio. Also, the sail can have a double purpose as a micrometeorite shield as discussed in the appendix. Of course, the increased performance offered under the conditions described should in practice also be weighed against the added complexity of the system.

Compared to a laser or microwave-driven sail, which is next to nuclear-based propulsion the other main candidate for interstellar propulsion with near-term technology, the sail is orders factors of magnitude 
smaller which is a considerable advantage when it comes to construction. Of course, also no external drivers are needed.

The presented concept was a one-stage design. Moving to a two or more stage design is of course still possible to increase delta-v. To further improve performance, it might be possible to use ${ }^{242 m} \mathrm{Am}$ (half life: 142 years) instead of $\mathrm{U}$ or $\mathrm{Pu}$ as fissile material, as ${ }^{242 \mathrm{~m}} \mathrm{Am}$ has the highest of all cross sections for thermal neutrons [20] and thus also a more efficient moderator, which may not need to work at cryogenic temperatures, can be used. As already discussed, there are proposed pathways to breed this material on an industrial scale [14].

Furthermore, Ronen et al. [22][23] have calculated that ${ }^{242 \mathrm{~m}} \mathrm{Am}$ can maintain sustained nuclear fission in a thin film of below 1 micrometer thickness, which would allow to do away with the fusion engine as driver for the fission reaction in the sail and adapt a fission-only approach. The elaboration of the latter concept is left for future research.

\subsection{Cost of thrust sail}

The current US Department of Energy sales price of ${ }^{239} \mathrm{Pu}$ for research quantities is about 10000 US $\$$ per gram [18], which would amount for a 100 ton sail to one trillion US\$. In the past, when nuclear weapons were mass manufactured, the actual fabrication cost could well have been at least an order of magnitude lower. Existing stock could also be used: as of the end of 2012, Russia's fissile material stock is estimated to include about 128 tonnes of weapons-grade plutonium and 695 tonnes of highly-enriched uranium [19].

As the raw material price (uranium oxide) out of which plutonium is bred, is only in the order of 50 US\$ per $\mathrm{kg}$, the cost can most probably be reduced by several orders of magnitude by process upscaling, if it is decided to develop a thrust sheet based starship for which much higher quantities are needed than for weapons fabrication. Nevertheless, the cost of deuterium for pure fusion based propulsion is about 5 US $\$$ per gram [20] and is thus much more affordable.

\subsection{Further work and testability}

Some factors were not covered in the preliminary calculations presented and are left for later work. These include more detailed moderator calculations and applying the calculated neutron energy spectrum to fission product generation instead of using the median, the effect of neutron reflection by the inert part of the sail and a more detailed system design. Furthermore, the effects of the non-uniformity of the neutron load to the sail which i.a. necessitates a more complicated sail regeneration strategy were not included. Also, the behavior of the fissile material layer under neutron bombardment should be studied. Possible embrittlement of the sail's backlayer and the thermal coupling between sail and heat radiators are also a topic needing further study. Due to lack of data, the model used in his work has significant simplifying assumptions. E.g., it assumes constant properties of the fissile layer on the sail. Furthermore, fission fragments could knock fissile atoms out of the sail before they can react with neutrons, lowering delta-v. A possible alleviation could be the use of fissile oxides such as uranium oxide as sail coating instead of a metallic coating, or a retention layer as already suggested by Mockel [9].

The fission sail concept - including many of the nonidealities listed above - is testable with current technology and a limited budget: a test setup could comprise a sheet a few $\mathrm{cm}^{2}$ in area on a cantilever for optical measurement and an accelerator-based neutron source. Accelerator-based cold neutron sources with a neutron flux density of $5 \cdot 10^{10} \mathrm{~cm}^{-2} \mathrm{~s}^{-1}$ are available [24], which would yield nanonewtons of thrust per $\mathrm{cm}^{2}$. Of course, for real deployment controlled nuclear fusion technology should also evolve further. 


\section{Conclusion}

The concept of a fissile element coated sail as a booster for nuclear fusion based rocket ships was introduced and studied. Whether or not adding the sail makes sense to optimize delta-v depends on the efficiency of the fusion based rocket, which is unknown at this moment. According to the calculations presented, the efficiency below which a fission sail makes sense is in the range of $31 \%$ to $38 \%$ for a neutral mass penalty for adding thes sail $r_{\text {mass }}$, and below $21 \%$ for a $r_{\text {mass }}=1.2$. From a first order design exercise, a $r_{\text {mass }}$ of around 1.1 is found to be realistic.

Altogether, the calculations presented show enough promise to justify further research into this propulsion technology.

\section{Acknowledgements}

We would like to thank all (co-)members of Icarus Interstellar, the Fourth Millennium Foundation and the I4IS for their inspiration, helpful discussion and advice, especially Robert Freeland, Jim French, Kelvin Long, Richard Obousy and lan Crawford. Also, special thanks to the FWO-Flanders for awarding a multidisciplinary research fellowship to Frederik Ceyssens.

\section{Appendix: Sail as micrometeorite shield}

The ensemble of the sail and the rocket's hull form a two-layer impact protection structure, a so-called Whipple shield. The multilayer structure is beneficial over a single-layer structure as the impact with the first ('bumper') layer will vaporize an incoming particle in the collision speed is high enough after which the debris can spread out in space, minimizing impact damage with the second ('wall') layer.

Hypervelocity impact on a Whipple shield is modeled by the following semi-empirical equation [37]:

$$
d_{p}=3.918 \cdot t_{w}^{2 / 3} \cdot \rho_{p}^{-1 / 3} \cdot \rho_{b}^{-1 / 9} \cdot V^{-2 / 3} \cdot S^{1 / 3} \cdot\left(\frac{\sigma_{w}}{70}\right)^{1 / 3}
$$

with $d_{p}$ the impacting particle diameter and $t_{w}$ the rear wall thickness in $\mathrm{cm}, \rho_{p}$ and $\rho_{w}$ the mass densities $\left[\mathrm{g} / \mathrm{cm}^{3}\right]$ of the incoming particle and the bumper layer, $V$ the incoming particle velocity $[\mathrm{km} / \mathrm{s}], S$ the spacing between bumper and second wall $[\mathrm{cm}]$ and $\sigma_{w}$ the yield stress of the second wall [ksi]. For reasonable values of these parameters as shown in table 4 , the model yields a maximum incoming particle diameter of $48 \mu \mathrm{m}$, which contrasts well with the size of interstellar dust particles, which ranges from submicrometer to micrometer diameters [38] [39].

\begin{tabular}{|l|l|}
\hline$t_{\mathrm{w}}[\mathrm{cm}]$ & 1 \\
\hline$\rho_{\mathrm{p}}\left[\mathrm{g} / \mathrm{cm}^{3}\right]$ & 2 \\
\hline$\rho_{\mathrm{b}}\left[\mathrm{g} / \mathrm{cm}^{3}\right]$ & 2 \\
\hline $\mathrm{V}[\mathrm{km} / \mathrm{s}]$ & $1 \% \mathrm{c}$ \\
\hline $\mathrm{S}[\mathrm{cm}]$ & $5 \cdot 10^{4}$ \\
\hline$\sigma_{\mathrm{w}}[\mathrm{ksi}]$ & 60 \\
\hline
\end{tabular}

Table 6: parameters for Whipple shield calculation 


\section{ADDENDUM}

After this work had been accepted, it was pointed out to us by mr. Koen Van Montfort while championing his Anais propulsion solution that lithium could also be used as fissile material, as ${ }^{6} \mathrm{Li}$ reacts with neutrons according to the following reaction:

${ }^{6} \mathrm{Li}+\mathrm{n}=>{ }^{4} \mathrm{He}(2.05 \mathrm{MeV})+\mathrm{T}(2.75 \mathrm{MeV})$

This reaction's cross section is over 4700 barns for $1 \mathrm{meV}$ neutrons and over 1000 barns for thermal neutrons .

If proven to be practical, lithium fuel would greatly reduce the cost of the thrust sail and also cause no additional neutron radiation.

Furthermore, it should be noticed that in equation (8) the inefficiency modelled by the factor $\eta_{F}$ still assumes unhampered neutron production. Therefore, $\eta_{F}$ models e.g. nozzle inefficiency, Bremsstrahlung etc. well, but not incomplete fuel burnup. If neutron production is relatively inefficient as well, it eventually becomes not advisable to add the fission thrust sail system to a fusion rocket.

\section{REFERENCES}

[1] K.E.Tsiolkovsky, The exploration of cosmic space by means of reaction devices, Scientific Review 5 (1903).

[2] W. Moore, A Treatise on the Motion of Rockets to which is added, An Essay on Naval Gunnery, G. and S. Robinson, London, 1813.

[3] G. Chapline, Fission fragment rocket concept, Nuclear Instruments and Methods in Physics Research Section A: Accelerators, Spectrometers, Detectors and Associated Equipment 271(1) (1988) 207-208.

[4] A. Bond, A. R. Martin, Project Daedalus reviewed, Journal of the British Interplanetary Society 39 (1986) 385-390.

[5] K.A. Beals, M. Beaulieu, F.J. Dembia, J. Kerstiens, D.L. Kramer, J.R. West, J.A. Zito, Project Longshot: An Unmanned Probe To Alpha Centauri, US Naval Academy, NASA-CR-184718 (1988).

[6] K.F. Long, R.K. Obousy, A. Hein, Project Icarus: Optimisation of nuclear fusion propulsion for interstellar missions, Acta Astronautica 68 (2011) 1820-1829.

[7] R.K. Obousy, K. Richard, Project Icarus: A 21st century interstellar starship study, Jourval of the British Interplanetary Society 65 (2012) 325-329.

[8] R.K. Obousy, A. C. Tziolas, K. F. Long, P. Galea, A. Crowl, L. A. Crawford, R. Swinney, A. Hein, R. Osborne, P. Reiss, Project Icarus: progress report on technical developments and design considerations, Journal of the British Interplanetary Society 64(11) (2011) 358.

[9] W.E. Mockel, Thrust-sheet propulsion concept using fissionable elements, AIAA Journal 15(4) (1977) 467-476.

[10] R.M. Freeland, Project Icarus: Fission-Fusion Hybrid Fuel for Interstellar Propulsion, Journal of the British Interplanetary Society 66 (2012) 290-296.

[11]T. Kammash, A Fusion Hybrid Propulsion System for Rapid Interplanetary Transport, 47th AIAA/ASME/SAE/ASEE Joint Propulsion Conference \& Exhibit 31 July - 03 August 2011. 
[12] E. A. C. Crouch, "Fission-product yields from neutron-induced fission." Atomic Data and Nuclear Data Tables 19(5) (1977) 417-532.

[13]J.R. Lamarsh, Introduction to nuclear Engineering, 2nd edition, Addison-Wesley publishing company, 1983, p. 95.

[14] Y. Ronen, M. Aboudy, D. Regev, Breeding of 242m Am in a Fast Reactor, Nuclear technology 153(2)(2006) 224-233.

[15] Data from National Nuclear Data Center, Brookhaven National Laboratory, http://www.nndc.bnl.gov/sigma (downloaded 1/10/2014)

[16] International Atomic Energy actinide data sheet, https://www-nds.iaea.org/sgnucdat/a5.htm

[17] nuclear data source: LANL nuclear data viewer: http://t2.lanl.gov/nis/data/ndviewer.html.

[18] Plutonium Certified Reference Materials Price List. U.S. Department of Energy. 2013. http://science.energy.gov/nbl/certified-reference-materials/prices-and-certificates/plutoniumcertified-reference-materials-price-list/

[19] Global Fissile Material Report 2013: Increasing Transparency of Nuclear Warhead and Fissile Material Stocks as a Step toward Disarmament, ${ }_{2}$ Seventh annual report of the International Panel on Fissile Material, October 2013

[20] Price from Sigma Aldrich for small quantities, retrieved in 2014

[21] A.G. Zelenkov et al, New measurements of the partial half-lives of an isomeric state of $242 \mathrm{~m} \mathrm{Am}$., Atomic Energy 47(6) (1979) 1024-1025.

[22] Y. Ronen, E. Shwageraus, Ultra-thin 242.Am fuel elements in nuclear reactors, Nuclear Instruments and Methods in Physics Research A 455 (2000) 442-451.

[23] Y. Ronen, M Aboudy, D Regev, A novel method for energy production using $242 \mathrm{mAm}$ as nuclear fuel, Nucl. Tech., 19 (2000) 407.

[24] K.Inoue, Y.Kiyanagi, H. Iwasa, An accelerator-based cold neutron source, Nuclear Instruments and Methods 192 (1982) 129-136.

[25] J.R. Lamarsh. Introduction to nuclear Engineering, 2nd edition, Addison-Wesley publishing company. 1983 p. 194

[26] National Nuclear Data Center http://www.nndc.bnl.gov/sigma/index.jsp?as=2\&lib=endfb7.1\&nsub=10

[27] G.E. Hansen and W.H. Roach, "Six and sixteen group cross sections for fast and intermediate critical assemblies" Los Alamos Scientific Laboratory report LAMS-2543 (November 1961)

[28]J.R.Lamarsh. Introduction to nuclear Engineering, 2nd edition, 1983, Addison-Wesley publishing company. p. 66

[29] F.S. Varley, Neutron scattering lengths and cross sections, Neutron News 3 (1992) 29-37.

[30] K. C. Ng, J. A. Caruso, Volatilisation of Zirconium, Vanadium, Uranium and Chromium Using Electrothermal Carbon Cup Sample Vaporisation into an Inductively Coupled Plasma, Analyst, 108 (1983) 476-480.

[31] J.M. Tournier, M. S. El-Genk, Liquid metal heat pipes radiator for space nuclear reactor power systems, Proc. 3rd International Energy Conversion Engineering Conference (IECEC-2005), August 2005.

[32] A.T.Mattick and A. Hertzberg, Liquid Droplet Radiator Technology Issues, Space Nuclear Power Systems vol II, 1984, pp. 427-435

[33] David G Elliott, Rotary Radiators for reduced space powerplant temperatures. Space Nuclear Power Systems vol II, 1984, 447-453.

[34]K.A. Beals, M. Beaulieu, F.J. Dembia, J. Kerstiens, D. L. Kramer, J. R. West, J. A. Zito, Project Longshot: An Unmanned Probe to Alpha Centauri. Topical project report NASA-CR-184718, 1988. 
[35] W. C. Young , R. G. Budynas, Roark's Formulas for Stress and Strain seventh edition, McgrawHill, 2002, 448-449.

[36] G. L. Matloff, E. Mallove, Solar sail starships: the clipper ships of the galaxy, Journal of the British Interplanetary Society 34 (1981) 371-380.

[37] Eric L. Christiansen, Design and performance equations for advanced meteoroid and debris shields, International Journal of Impact Engineering vol 14 pp. 145-156, 1993

[38] G. Matloff, L. Johnson, Applications of the Electrodynamic Tether to Interstellar Travel, Journal of the British Interplanetary Society 58 (2005) 398-402.

[39] S. H. Kim, P. G. Martin, P. D. Hendry, The size distribution of interstellar dust particles as determined from extinction, The Astrophysical Journal 422 (1994) 164-175. 